Egyptian

Orthodontic Journal

\title{
STUDY OF THE EFFECT OF A FILLED FLUORIDE RELEASING ENAMEL SEALANT VERSUS FLUORIDE VARNISH ON INITIALLY DEMINERALIZED ENAMEL
}

\author{
Zaher $\mathrm{A}^{*}$, El-Harouny $\mathrm{N}^{*}$, Hanafy $\mathrm{S}^{* *}$, Abdel-Haffiez $\mathrm{S}^{* * *}$
}

ABSTRACT:

Development of white spot lesions (WSL) adjacent to fixed orthodontic appliances is of fairly common occurrence. Such lesions can appear in patients' mouth within a span of 4 weeks. Aim: This randomized controlled in vitro study was conducted to compare the effect of the use of a filled, fluoride releasing, light cure enamel sealant (Pro Seal) versus fluoride varnish (Fluor Protector) on artificially induced white spots. Methods: Thirty human premolar teeth with artificially induced WSL were photographed using stereomicroscope. Specimens were treated with either fluoride varnish, Pro Seal or used as controls, and then were subjected to an acid challenge. Specimens were then photographed again using the stereomicroscope. Stereomicroscopic pictures were used to compare intensity and scoring of white spot lesions on the teeth before and after acid challenge. Results: The severity of WSL in the specimens treated with either Pro Seal or fluoride varnish remained the same. Diffusion of the WSL and cavitations of enamel surface were seen in the control group. No statistically significant difference was found between the Pro Seal and the fluoride varnish groups regarding their effect on progression of artificially induced white spot lesion when compared to the

\footnotetext{
* Professor of Orthodontics, faculty of dentistry, Alexandria University.

${ }^{* *}$ Professor of Dental Biomaterials, faculty of dentistry, Alexandria University.

*** Assistant lecturer of Orthodontics, faculty of dentistry, Alexandria University.
} 
Egyptian

Orthodontic Journal

control group. Conclusion: Both Pro Seal and fluoride varnish showed significant effect on prevention of progression of artificially induced white spot lesions when compared to the control group.

\section{INTRODUCTION}

Development of white spot lesions adjacent to fixed orthodontic appliances is a prevalent iatrogenic effect of orthodontic therapy. Such lesions can be clinically induced within a span of 4 weeks ${ }^{1,2,3}$, therefore, the occurrence of white spot lesions during ongoing orthodontic treatment is not an uncommon finding, especially in patients with poor oral hygiene ${ }^{4}$.

If such lesions were left without intervention to prevent their progression, they may turn into true cavitations due to the continuous acidic environment and the drop in plaque $\mathrm{pH}$ accompanying fixed orthodontic appliances 5 . Following a strict oral hygiene protocol can prevent white spot lesion progression; however, studies have indicated that full patient compliance with oral hygiene instructions is unlikely. ${ }^{6,7}$

Therefore, an ideal method used to control WSL progression should be easy for the clinician to use and independent of patient oral hygiene habits. The application of fluoride varnish or resin sealant to initially demineralized enamel has been studied in the literature as one of the methods to control their progression.

Fluoride varnish application to initially demineralized enamel lesions showed promising control of lesion progression. Weinstein et $\mathrm{al}^{8}$ applied Fluoride varnish to decalcified maxillary incisors in children, and found $51 \%$ of 73 decalcified teeth at baseline to be sound after six-month recall. Fluoride varnish application in children controlled progression of active enamel lesions; with only $18.8 \%$ of the active enamel lesions progressed after nine months of fluoride varnish application versus $62.2 \%$ of lesion progression in the control group. ${ }^{9}$ Weekly fluoride varnish application resulted in significant reduction in the mesiodistol and incisogingival dimensions of the active WSL in the anterior permanent teeth after 4 weeks. $^{10}$ 
Egyptian

Orthodontic Journal

Sealing initially demineralized enamel lesions showed ability to control lesion progression. Martignon, Ekstranda and Ellwood ${ }^{11}$ applied resin sealant in a split-mouth design study to one randomly selected proximal enamel lesion (test) in each patient of 82 adults. Other lesions were left as controls. After 18 months, radiographic evaluation of the lesions comparing them to baseline radiographs showed; only $44 \%$ of the test lesions were progressive compared to $84 \%$ of the controls. Trairatvorakul, Kladkaew and Songsiripradabboon ${ }^{12}$ applied a resin sealant, fluoride-containing sealant and fluoride varnish to artificially induced WSL in vitro. Specimens were thermocycled and subjected to caries challenge, and then sectioned and examined under polarized light microscope. All lesion areas underneath the materials applied to the experimental groups were significantly smaller compared with those of the control group. Specimens treated with fluoride varnish showed less lesion depth compared to those treated with enamel sealant. Martignon et $\mathrm{al}^{13}$ in their split-mouth design study on primary molar teeth showed that sealing initial carious lesions effectively arrested carious lesions both after 1 year and 2.5 years of follow-up compared to the controls, comparing baseline radiographs to follow-up ones at 1 year and 2.5 years periods. Paris, Hopfenmuller and Meyer-Lueckel ${ }^{14}$ found that $37 \%$ of the initially demineralized enamel lesions progressed in the control group, versus only $7 \%$ of the resin sealed enamel lesions after 18 months follow-up.

Ekstrand, Bakhshandeh and Martignon ${ }^{15}$ found a better control of non-cavitated proximal enamel lesions when both resin sealant and fluoride varnish were used for lesion treatment compared to fluoride varnish treatment alone. In their one year split-mouth study, combining resin and fluoride varnish treatment lowered the number of the progressed lesion into half those treated with fluoride varnish alone.

However sealants showed a significant protection against white spot lesion progression, their durability on tooth surface is questionable. Sealants showed to polymerize poorlydue to oxygen inhibition of polymerization $^{16,17}$ and sealants failed to leave a film on the enamel surface after removal of the air-inhibited layer ${ }^{18}$. Sealants-reduced resistance to abrasion ${ }^{19}$ have limited their benefit. Steffen ${ }^{20}$ showed that the vast majority of the applied light-cured resin (Transbond) was removed by the chemical attack of cola soft drinks, leaving small islands of sealant that withstood the acid attack.

Volume 42 - December 2012 
To overcome the problems encountered in sealant use because of oxygen inhibition of polymerization, and reduced resistance to abrasion, Reliance Orthodontics produced Pro seal; a highly filled fluoridereleasing sealant which offers a $100 \%$ surface polymerization with no surface oxygen inhibited layer. ${ }^{21}$ The high filler content in Pro Seal in addition to its $100 \%$ surface polymerization offered satisfactory mechanical resistance; and Pro Seal withstood mechanical tooth brushing challenge for prolonged periods equivalent to two years in patient's mouth. ${ }^{22,23}$ Moreover, Pro Seal releases fluoride in a decreasing rate ${ }^{24}$.

This study was carried out to test the null hypothesis that no difference on white spot lesions progression would be observed with the use of either fluoride varnish (Fluor protector) or highly filled, fluoride releasing enamel sealant (Pro Seal).

\section{MATERIAL AND METHODS}

Thirty teeth were used to study the effect of Pro-Seal ${ }^{*}$ versus fluoride $\operatorname{varnish}^{* *}$ on initially demineralized enamel. All teeth were cleansed, polished with a mixture of nonfluoridated pumice and water, rinsed under running water and then dried. Teeth were completely covered with adhesive tape leaving a small window $(5 \times 4 \mathrm{~mm})$ on the middle of the buccal surface, and then were immersed in standard ten Cate demineralizing solution $(\mathrm{pH} 4.4)$ and were left in the demineralizing solution until all the teeth had artificial white spots of a base line of score 2 according to the following scoring system ${ }^{25}$ :

$0=$ no visible white spots

$1=$ slight visible white spots

$2=$ excessive visible white spots

$3=$ white spots with cavitation

Adhesive tape was removed; the teeth were washed under running water and dried with moisture and oil free jet of air. Each tooth was photographed using the stereomicroscope ${ }^{26}$.

\footnotetext{
* Pro Seal, Reliance Orthodontic Products, Itasca, Illinois

** Fluor Protector; Ivoclar Vivadent, Amherst, Mass
} 
Egyptian

Orthodontic Journal

The teeth were numbered and randomly assigned using a random number generator ${ }^{*}$ into 3 groups, each consisting of 10 teeth, according to the treatment the enamel received:

Group I: Pro seal (filled sealant) was applied to the enamel surface according to manufacturer's instructions. The whole enamel surface was etched using 37\% phosphoric acid gel for 30 seconds, rinsed under running water, and then dried with oil- and moisture-free compressed air. A single coat of Pro seal was applied to the etched enamel surface, thinned with a gentle stream of oil- water- free compressed air and light cured for 20 seconds using a halogen bulb ${ }^{* *}$.

Group II: A thin layer of Fluoride varnish was applied to the pumiced dry enamel surface using an applicator brush. The applied varnish was evenly dispersed and dried with a gentle stream of oil- and moisture-free air. Fluoride varnish was allowed to set undisturbed on enamel surface for 12 hours according to the manufacturer's instructions.

Group III: Acted as control with no further treatment of the white spot area.

The teeth were photographed again using stereomicroscope following material application to asses any changes in white spot severity following material application.

The teeth were stored in artificial saliva solution, in separate beakers, and cycled in standard ten Cate demineralizing solution for 1 hour every 11 hours. After 8 weeks, white spots were photographed using stereomicroscope to assess changes in white spots severity.

\section{RESULTS}

Neither the application of fluoride varnish nor Pro Seal to the initially demineralized enamel changed the severity or the appearance of the artificially induced white spots.

After 8 weeks, the severity and appearance of WSL of all the specimens in the Pro Seal group remained the same (score 2). Neither diffusion of the white spots nor cavitation was observed on any of the specimens of this group.

\footnotetext{
*Urbaniak, G. C., \& Plous, S. (2009). Research Randomizer (Version 3.0)

** Elipare II, ESPE GmbH and Co., Seefeld, Germany.
} 
In the varnish group, 8 teeth kept the same appearance of the white spot lesions, whereas, 2 teeth showed diffusion of the lesions to include the whole buccal surface, but no cavitation were seen in any of the specimens of this group.

In the control group, 4 teeth showed diffusion of the white spot lesions to include the whole buccal surface, whereas, 6 teeth showed diffusion of the white spot lesion to include the whole buccal surface with cavitation (score 3 ) seen on the buccal surface. A representative premolar from each group is shown in (fig.1)

No statistically significant difference was found between the effect of either Pro Seal or fluoride varnish on severity of artificially induced white spot lesions, however, both material showed significant effects on prevention of white spot lesion progression and development of cavitation when compared to the control group.A Comparison of severity of white spots after 8 weeks among study groups is shown in Table 1.

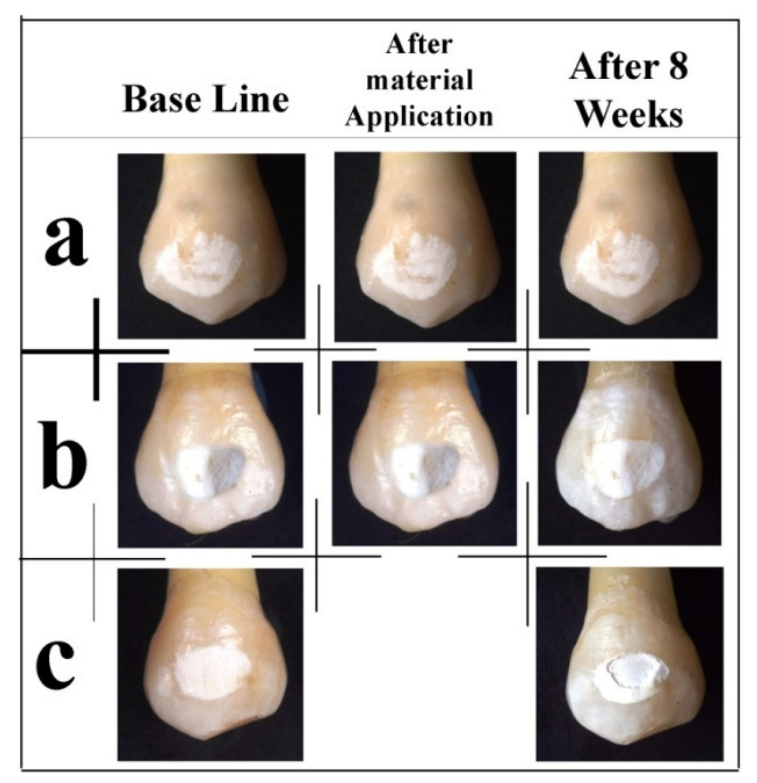

Fig 1. Change in severity of white spot lesion after material application and after 8 weeks in a representative premolar from each group. (a) Pro Seal group, (b) Fluoride varnish group and (c) control group. 
Egyptian

Orthodontic Journal

Table 1: Comparison of severity of white spots after 8 weeks among study groups.

\begin{tabular}{|c|c|c|c|c|}
\hline \multirow[b]{2}{*}{ White spots } & \multicolumn{3}{|c|}{ Groups } & \multirow[b]{2}{*}{$\begin{array}{l}\text { Total } \\
\mathrm{N}(\%)\end{array}$} \\
\hline & $\begin{array}{c}\text { Prosealgroupa } \\
\text { N }(\%)\end{array}$ & $\begin{array}{l}\text { Flouride varnish } \\
\text { groupa } \mathrm{N}(\%)\end{array}$ & $\begin{array}{c}\text { Control group b } \\
\mathrm{N}(\%)\end{array}$ & \\
\hline Score 0 (No white spots) & 0 & 0 & 0 & 0 \\
\hline Score 1 (Slight white spot) & 0 & 0 & 0 & 0 \\
\hline $\begin{array}{l}\text { Score } 2 \text { (Excessive white } \\
\text { spot) }\end{array}$ & $10(100)$ & $10(100)$ & $4(40)$ & $24(80)$ \\
\hline $\begin{array}{l}\text { Score } 3 \text { (White spot with } \\
\text { cavitation) }\end{array}$ & 0 & 0 & $6(60)$ & $6(20)$ \\
\hline Total: N (\%) & $10(100)$ & $10(100)$ & $10(100)$ & $30(100)$ \\
\hline $\begin{array}{l}\mathrm{X} 2 \\
\mathrm{P} \text { value }\end{array}$ & & $\begin{array}{c}15.00 \\
<0.0001 *\end{array}$ & & \\
\hline
\end{tabular}

*: Statistically significant at $\mathrm{P} \leq 0.05$

$\mathrm{a}$ and $\mathrm{b}$ : different letters denote significant differences between groups

\section{DISCUSSION}

It is not uncommon to see (WSLs) in patients undergoing orthodontic treatment, as enamel demineralization can occur within a month after the placement of the fixed orthodontic appliance.$^{1-3}$ In this study, investigation of the effect of applying Pro Seal versus fluoride varnish on artificially induced (WSLs) was tested.

All the teeth in the control group showed extension and progression of demineralization to involve the whole enamel surface and six teeth of ten progressed to cavitation. In the natural state, there is demineralization and remineralization continually taking place, ${ }^{27}$ with the minerals of the dental enamel being in equilibrium with its environment and the saliva contains all the necessary elements for hydroxyapatite crystal growth. However, with the continuous or persistent drop in plaque $\mathrm{pH}$, the amount of remineralization cannot totally overcome the amount of demineralization and progression of demineralized lesions can take place.

In the fluoride varnish group, no teeth showed cavitation, however, none of the specimens showed regression of the lesionin spite of the suggestion that placement of fluoride varnish either over or around the 
Egyptian

Orthodontic Journal

lesion can promote remineralization ${ }^{28}$. It could be explained by the fact that high concentration fluoride preparations such as fluoride varnish may plug diffusion pathways of enamel by hydroxyapatite crystals as hyperremineralization. ${ }^{29}$ This can impede fluoride, calcium, and phosphate ions penetration through the surface zone and their precipitation on sound enamel at the margins of the subsurface demineralized lesion ${ }^{30}$, thus the recommendations of the workers in this field that remineralization of small enamel lesions should be attempted using low fluoride preparations, to avoid arresting the lesion and obtunding the surface layer ${ }^{31,32}$.

Todd et $\mathrm{al}^{33}$ hypothesized that the dissolution of the fluoride varnish by the moist environment or its breakage off the enamel surface through mechanical brushing; exposes the enamel to the high concentration of fluoride present in the remaining adjacent varnish. However, in the current study, varnish breaks or dissolution may not have occurred, as specimens were neither subjected to any mechanical challenges nor thermocycling, which may be the reason why enamel lesion regression was not seen in the current study. Trairatvorakul, Kladkaew and Songsiripradabboon ${ }^{12}$ showed fluoride varnish ability to cause regression of some of the lesions in vitro. They subjected the specimens to thermocycling after material application to the lesions which may have allowed varnish layer breaks to occur. In vivo studies ${ }^{8,9,10}$ showed fluoride varnish ability to cause WSL regression. Oral environment with its mechanical, chemical and thermal challenges can easily cause fluoride varnish layer breaks or dissolution. Once the varnish starts to break off, enamel becomes exposed to the high concentration of fluoride present in the remaining varnish which can help to enhance the remineralization process.

In the current study, Pro Seal was able to keep all the lesions static with no progression or regression of any of the lesions. Todd and co-workers $^{24}$ postulated that if a barrier completely covered an existing white spot lesion, no remineralization would take place, because the calcium and phosphorous ions in the saliva are prevented from reaching the white spot lesion. Therefore, a protective sealant that completely covers an existing lesion would only inhibit further demineralization and does not have any remineralization effect. In vivo studies using non-filled resins ${ }^{11,13,14}$ showed regression of some of the lesions after sealant application. Non-filled resins are unable to resist mechanical abrasion or chemical attack ${ }^{20}$. Usually, resin application in vivo would not be as 
reliable as its application in vitro; because of isolation difficulties which may lead to voids in the resin layer. Moreover, studies showed incomplete or even lacking polymerization of the sealant layer due to oxygen inhibition of polymerization ${ }^{16,17,18}$. Breaks in sealant layer and voids resulting from difficulty in application in addition to sealant wear or lack of complete polymerization may facilitate microleakage ${ }^{34}$ and the access of the saliva through sealant, providing minerals necessary for lesion remineralization allowing for its regression. On the contrary, Pro Seal is highly filled and offers a $100 \%$ surface polymerization with no surface oxygen inhibited layer, which is supposed to provide adequate resistance to mechanical wear and complete polymerization of the sealant layer allowing complete and prolonged sealing of the enamel surface.

In this study the lesions were assessed only by examining the surface changes which may not reveal what really happens in the lesion bulk and at the subsurface layer. However Weinstein et $\mathrm{al}^{8}$ found that about half the teeth with initial enamel lesion at baseline turned to be sound after six months with fluoride varnish application and Ferreira et $\mathrm{al}^{10}$ recorded a frank reduction in lesion dimensions after weekly application of fluoride varnish, no major surface changes were observed in the treated enamel lesions in this study. However, changes in lesion depth or extension may have occurred and passundetected when examining the lesion surface.

Trairatvorakul, Kladkaew and Songsiripradabboon ${ }^{12}$ applied a resin sealant, fluoride-containing sealant and fluoride varnish to artificially induced WSL in vitro, and subjected the specimens to an acid challenge before sectioningto examine them under polarized light microscope. They found less lesion depth with all treatments compared to the controls. This may strengthen our findings that sealing initial carious lesions or fluoride varnish application can efficiently arrest lesion progression.

Martignon, Ekstranda and Ellwood ${ }^{11}$,Martignon et $\mathrm{al}^{13}$ and Ekstrand, Bakhshandeh and Martignon ${ }^{15}$ assessed their lesions radiographically which allowed detecting changes occurring in the lesion extension throughout tooth structure. They observed arrest of majority of lesions with sealing initial carious lesions. This confirms our findings that sealing initial carious lesions can efficiently arrest lesion progression. 
Egyptian

Orthodontic Journal

\section{CONCLUSION}

1. Once white spot lesions develop, their progression is likely and may lead to cavitation.

2. Application of fluoride varnish or Pro Seal to white spot lesions appeared to be effective to stop the progression of these lesions, thought did not show potency for their reversal.

\section{REFERENCES}

1) Øgaard B, Rolla G, Arends J: Orthodontic appliances and enamel demineralization. Part 1. Lesion development. Am J Orthod Dentofacial Orthop 1988;94:68-73.

2) Gorton J, Featherstone JDB. In vivo inhibition of demineralization around orthodontic brackets. Am J Orthod Dentofacial Orthop $2003 ; 123: 10-4$.

3) Glatz EGM, Featherstone JDB. Demineralization related to orthodontic bands and brackets - a clinical study [abstract]. Am J Orthod 1985;87:87.

4) Guzma'n-Armstrong S, Chalmers J, Warren JJ. White spot lesions: Prevention and Treatment. Am J Orthod Dentofacial Orthop 2010;138:690-6.

5) Bishara S, Ostby A. White Spot Lesions: Formation, Prevention, and Treatment. Semin Orthod 2008;14:174-182.

6) Geiger AM, Gorelick L, Gwinnett A J, Benson BJ. Reducing white spot lesions in orthodontic patients with fluoride rinsing. Am J Orthod Dentofac Orthop 1992;101:403-7.

7) Shannon IL. Prevention of decalcification in orthodontic patients. J Clin Orthod 1981;15:694-706.

8) Weinstein P, Domoto P, Koday M, Leroux B. Results of a promising open trial to prevent baby bottle tooth decay: a fluoride varnish study. ASDC J Dent Child. 199;61:338-41. 
Egyptian

Orthodontic Journal

9) Autio-Gold JT, Courts F. Assessing the effect of fluoride varnish on early enamel carious lesions in the primary dentition. J Am Dent Assoc. 2001;132:1247-53.

10) Ferreira JM, Aragão AK, Rosa AD, Sampaio FC, Menezes VA. Therapeutic effect of two fluoride varnishes on white spot lesions: a randomized clinical trial. Braz Oral Res.2009;23:446-51.

11) Martignon S,. Ekstranda KR, Ellwood R. Efficacy of sealing Proximal Early Active Lesions: An 18-Month Clinical Study Evaluated by Conventional and Subtraction Radiography. Caries Res 2006; $40: 382-388$

12) Trairatvorakul C, Kladkaew S, Songsiripradabboon S. Active Management of Incipient Caries and Choice of Materials. J DENT RES 2008;87: 228.

13) Martignon S, Tellez M, Santamaría RM, Gomez J, Ekstrand KR. Sealing distal proximal caries lesions in first primary molars: efficacy after 2.5 years. Caries Res. 2010;44(6):562-70

14) Paris S, Hopfenmuller W, Meyer-Lueckel H. Resin Infiltration of Caries Lesions an Efficacy Randomized Trial. JDR 2010;89:823-826

15) Ekstrand KR, Bakhshandeh A, Martignon S. Treatment of proximal superficial caries lesions on primary molar teeth with resin infiltration and fluoride varnish versus fluoride varnish only: efficacy after 1 year. Caries Res. 2010;44:41-6.

16) Zachrisson B.U, Heimglrd E, Ruyter E, Mjör I.A. Problems with sealants for bracket bonding. Am J Ortho Dentfac Orthop 1979;75:641-649.

17) Joseph V.P, Rossouw P.E, Basson N.J. Some "sealants" seal A scanning electron microscopy (SEM) investigation. Am J Orthod Dentofac Orthop 1994;105:362-8.

18) Ceen R.F, Gwinnett A.J. microscopic evaluation of the thickness of sealants used in orthodontic bonding. Am J Ortho 1980;78:623-629.

19) Hughes D.O, Hembrse J.H, Weber F.N. Preparations to prevent enamel decalcification during orthodontic treatment. An in vitro study. Am J Ortho 1979;75:416-20. 
Egyptian

Orthodontic Journal

20) Steffen J.M. the effect of soft drinks on etched and sealed enamel. Angle Orthod 1996;66:449-456.

21) The Bonding Bulletin. Itasca, Ill: Reliance Orthodontic Products Inc; Spring 2003.

22) $\mathrm{Hu} \mathrm{W}$, Featherstone J. Prevention of enamel demineralization: An in-vitro study using light-cured filled sealant. Am J Orthod Dentofacial Orthop 2005;128:592-600.

23) Buren J, Staley R, Wefel J, Qian F. Inhibition of enamel demineralization by an enamel sealant, Pro Seal: An in-vitro study. Am J Orthod Dentofacial Orthop 2008;133:S88-94.

24) Soliman M, Bishara S, Wefel J, Heilman J, Warren J. Fluoride Release Rate from an Orthodontic Sealant and Its Clinical Implications. Angle Orthod 2006;76:282-288.

25) Gorelick L, Geiger A, Gwinnett A. Incidence of white spot formation after bonding and banding. Am J Ortho 1982;81:93-98.

26) Zaher A, Raslan H, Ismail H, Ali P.N. study of the effect of topically applied oral gel formulas in the preventiom and treatment of early enamel decalcification (In Vitro study). Egyp Ortho J 2007;31:1-25.

27) Willmot D. White Spot Lesions After Orthodontic Treatment. Semin Orthod 2008;14:209-219.

28) Castellano JB, Donly KJ (2004). Potential remineralization of demineralized enamel after application of fluoride varnish. Am J Dent 17:462-464.

29) O'Reilly MM, Featherstone JDB: Demineralization and remineralization around orthodontic appliances: an in vivo study. Am J Orthod Dentofacial Orthop 92:33-40,1987.

30) Silverstone LM, Hicks MJ, Featherstone MJ: Dynamic factors affecting lesion initiation and progression in human dental enamel. Part I. The dynamic nature of enamel caries. Quintessence Int 19:683-711, 1988. 
31) Lee Linton J: Quantitative measurements of remineralization of incipient caries. Am J Orthod Dentofacial Orthop 104:590-597, 1996.

32) Lagerweij MD, Damen JJM, Stookey GK: Remineralization of small lesions by fluoride. J Dent Res 76:16, 1997.

33) Todd M, Staley R, Kanellis M, Donly K, Wefel J. Effect of a fluoride varnish on demineralization adjacent to orthodontic brackets. Am J OrthodDentofacialOrthop 1999;116:159-67.

34) Ferreira JM, Aragão AK, Rosa AD, Sampaio FC, Menezes VA. Therapeutic effect of two fluoride varnishes on white spot lesions: a randomized clinical trial. Braz Oral Res.2009;23(4):446-51. (abstract) 